\title{
Adverse Events and Risk Factors of Blood Transfusion in Cardiovascular Surgery: A Prospective Cohort Study
}

Ana Paula Tagliari, ${ }^{1,2}{ }^{\circledR}$ Lucas Molinari Veloso da Silveira, ${ }^{1 \oplus}$ Adriano Nunes Kochi, ${ }^{1,2}$ Anderson Castro de Souza, ${ }^{\circledR}$ Marcelo Curcio Gib, ${ }^{1,2}$ Tanara Martins de Freitas, ${ }^{1,2}$ Cristiano Blaya Martins, ${ }^{1,2}$ Leandro Totti Cavazzola, ${ }^{1,2}$ Orlando Carlos Belmonte Wender ${ }^{1,2}$

Universidade Federal do Rio Grande do Sul (UFRGS),' Porto Alegre, RS - Brazil

Hospital de Clínicas de Porto Alegre (HCPA), ${ }^{2}$ Porto Alegre, RS - Brazil

\section{Abstract}

Background: Hemodilution, transoperative bleeding and cardiopulmonary bypass (CPB) are some of the factors associated with high transfusion rates in cardiac surgery.

Objective: To analyze the incidence of blood transfusion and early postoperative outcomes in cardiac surgery patients.

Methods: Cohort study of patients undergoing cardiac surgery in a university hospital, consecutively enrolled from May 2015 to February 2017. Data were prospectively collected and comparisons were made between two patients' groups: transfused and not transfused. Student's t-test, chi-square test, and logistic regression were used, and a p-value $<0.05$ was considered significant.

Results: Among the 271 patients evaluated, 100 (37\%) required transfusion in the transoperative (32.1\%) and/or postoperative periods (19.5\%). The following predictors of transfusion were identified by multivariate analysis: EuroScore II (OR 1.2); chronic kidney disease (CKD) (OR 3.2); transoperative bleeding $\geq 500 \mathrm{~mL}$ (OR 6.7); baseline hemoglobin $(\mathrm{Hb}) \leq 10 \mathrm{~g} / \mathrm{dL}$ (OR 11.5); activated partial thromboplastin time (aPTT) (OR 1.1) and CPB duration (OR 1.03). Transfusion was associated with prolonged mechanical ventilation ( $\geq 24 \mathrm{~h})(2.4 \%$ vs. $23 \%)$, delirium (5.9\% vs. $18 \%)$, bronchopneumonia $(1.2 \%$ vs. $16 \%)$, acute renal failure (3.5\% vs. $25 \%)$, acute on CKD $(0.6 \%$ vs. $8 \%)$, stroke

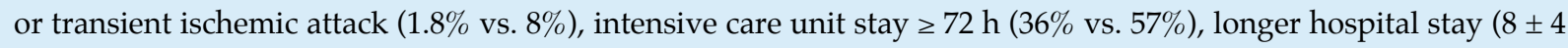
days vs. $16 \pm 15$ days), as well as increased early mortality (1.75\% vs. $15 \%)$.

Conclusion: EuroScore II, CKD, major transoperative bleeding, preoperative $\mathrm{Hb}$ and aPTT values and CPB time were independent predictors of transfusion, which was associated with a higher rate of adverse outcomes, including early mortality. (Int J Cardiovasc Sci. 2019;32(6):565-572)

Keywords: Cardiac Surgical Procedures/mortality; Blood Transfusion; Intraoperative Care/adverse effects; Postoperative Complications / prevention and control; Risk assessment.

\section{Introduction}

Hemodilution, transoperative bleeding and cardiopulmonary bypass (CPB) are some of the factors associated with high transfusion rates in cardiac surgery. ${ }^{1}$ The prevalence of patients undergoing cardiac surgery who receive blood components is unknown, with values varying from $10 \%$ to $95 \% .^{2-4}$ Such diversity is partly due to different local practices and institutional protocols.
A Canadian retrospective study documented a red blood cell (RBC) transfusion rate ranging from $23.8 \%$ to $51.9 \% .{ }^{1}$ In another study, transfusion rates in coronary artery bypass grafting (CABG) varied from 26.5 to $71.3 \%$.

Moreover, as noted by Vonk et al., ${ }^{6}$ there was $28 \%$ reduction in $\mathrm{RBC}$ transfusion in the last 10 years, with non-significant change in the use of fresh frozen plasma (FFP) or platelets. In 2011, 50\% and $60 \%$ of patients needed FFP and platelets, respectively. ${ }^{6}$ 
If, in one hand anemia is an independent risk factor for morbidity and mortality by reducing oxygen supply, leading to ischemic injury, ${ }^{7}$ on the other hand, the immune response caused by transfusion could be a potential harm factor. ${ }^{8}$

However, clinical trials such as TRACS ${ }^{9}$ and TITRe $2,{ }^{10}$ which compared restrictive versus (vs) liberal RBC transfusion strategies, have shown non inferiority for a composite endpoint of 30-day all-cause mortality and severe morbidity [cardiogenic shock, acute respiratory distress syndrome or acute renal failure (ARF)] during the hospital stay (10\% liberal vs. $11 \%$ restrictive) ${ }^{9}$ as well as for infectious or ischemic events $(35.1 \%$ vs. $33.0 \%) .{ }^{10}$ RBC transfusion was an independent risk factor for 30days clinical complications or death [hazard ratio (HR) for each unit transfused $=1.2 ; 95 \%$ confidence interval (CI) $1.1-1.4] .^{10}$

Analyzing long-term results, the recent TRICS trial demonstrated that, in moderate-to-high risk for death patients, a restrictive transfusion strategy (hemoglobin $<7.5 \mathrm{~g} / \mathrm{dL}$ intra or postoperatively) was non-inferior to a liberal strategy [hemoglobin $<9.5 \mathrm{~g} / \mathrm{dL}$ in the intensive care unit (ICU) or $<8.5 \mathrm{~g} / \mathrm{dL}$ in the non-ICU ward] in terms of death, myocardial infarction, stroke or new dialysis in 6-months (17.4\% vs. $17.1 \%$; $95 \%$ CI $0.87-1.18){ }^{11}$

Choosing between a liberal or a restrictive RBC transfusion strategy has been a major concern and, although clinical trials have supported more restrictive practices, some authors are still attempting to identify an "accurate" hemoglobin threshold for transfusion. ${ }^{12}$

In view of the clinical relevance and persistently high transfusion rates, we believe that recognition of modifiable risk factors and adverse events is the first step towards changing our daily practice.

\section{Objectives}

To analyze the incidence of blood transfusion in patients undergoing cardiovascular surgery in a tertiary university hospital in southern Brazil, between May 2015 and February 2017, as well as to analyze adverse events and risk factors associated with the transfusion.

\section{Methods}

Analysis of a prospective cohort of patients submitted to cardiovascular surgery, consecutively enrolled from
May 2015 to February 2017. Patients were divided into two groups according to whether or not they received any blood products (RBC, FFP or platelets), and were followed until hospital discharge or up to 30 days after the procedure, in order to evaluate early postoperative adverse outcomes.

All patients older than 18 years old undergoing cardiovascular surgeries at Hospital de Clinicas de Porto Alegre, a tertiary university hospital in southern Brazil, were invited to participate in the study. Patients who did not agree to participate and those who did not sign the informed consent form were excluded. The project was approved by the research ethics committee of the Hospital de Clinicas de Porto Alegre (approval number: 15-0332). All procedures were in accordance with the ethical standards for human experimentation and with the 1975 Helsinki Declaration revised in 2008.

Mortality and other postoperative outcomes were considered early if they occurred before hospital discharge or up to 30 days after surgical intervention. The outcome "other infections" was considered positive if the patient had superficial (e.g. saphenectomy infection) or deep wound infection (e.g. osteomyelitis or mediastinitis), infective endocarditis, sepsis or bacteremia.

The use of anticoagulant or antiplatelet agents was considered recent if the patient received unfractionated heparin or low molecular weight heparin at therapeutic doses in the 24 hours preceding surgery, warfarin or clopidogrel in the last 5 days or non-vitamin $\mathrm{K}$ antagonist oral anticoagulants (NOACs) in the last 48 hours. No patient used any other anticoagulant medication.

\section{Statistical analysis}

Data were obtained by clinical interview or review of electronic medical records, stored in a service database and analyzed using the Statistical Package for Social Sciences (SPSS) 18.0 software.

Quantitative variables were described as mean (M) and standard deviation (SD) and qualitative variables as absolute number and percentages. Independent samples t-test was performed for continuous variables whereas the chi-square test was used to compare categorical variables. Normality test and non-parametric tests were not performed, since parametric tests are considered robust even for non-normal distributions and skewed data once the sample size is deemed sufficiently large (more than 40 individuals). ${ }^{13-15}$ 
In order to identify variables associated with outcomes, univariate analyses were performed. Then, variables with statistical significance were added to a multivariable logistic regression model. A bilateral p-value $<0.05$ was considered significant.

Based on the study by Murphy et al., ${ }^{16}$ in which the observed 30-day mortality was 5\% in those who received RBC and $1 \%$ in those who did not, a sample size of 164 patients was estimated considering an $\alpha$ value of 0.05 and a desired power of 0.80 .

\section{Results}

Of the 271 patients evaluated, $100(37 \%)$ required transfusion of some blood product during transoperative [87 (32.1\%)] and/or postoperative periods [53 (19.5\%)]. Baseline characteristics are shown in Table 1.

Transoperative bleeding $\geq 500 \mathrm{~mL}$ was observed in 11 patients who did not require transfusion $(6.4 \%)$ and in $40(40 \%)$ who required it. The other transoperative characteristics are presented in Table 2.

The type of transfusion stratified by the operative period is displayed in Table 3. Predictors of RBC transfusion in univariate and multivariate analyses are shown in Table 4.

Reintervention was indicated in 21 patients $(7.7 \%), 11$ (52.3\%) of them due to increased postoperative bleeding or cardiac tamponade, all of them required blood transfusion. Patients who received blood transfusion presented higher early postoperative complication rates, as described in Table 5.

\section{Discussion}

Dilutional anemia, CPB-related thrombocytopenia, coagulation disorders due to medications, major surgery and hypothermia contribute to high rates of blood transfusion in cardiac surgery, despite a current trend for restrictive protocols.

In our sample of 271 patients, prospectively and consecutively enrolled, we observed a general transfusion rate of $37 \% ; 28.8 \%$ of them required $\mathrm{RBC}$, $22.1 \%$ platelets and $14.4 \% \mathrm{FFP}$, values similar to those in the literature..$^{1,5,6,9,10}$

We emphasize that, in our hospital, decisions about transfusion are a jointly made by the surgical, anesthetic and intensive care teams, who try to follow the best current evidence, but also take into account their experience and understanding of each situation, making the numbers presented here closer to real life.

We observed that some preoperative characteristics were transfusion predictors, such as anemia and anormal coagulation tests [activated partial thromboplastin time (aPTT) and international normalized ratio (INR)], although platelet count was not.

Predictors of blood transfusion in our analyses were similar to the TRACS trial, which showed higher transfusion rates in patients with previous cardiac surgery $(\mathrm{OR}=8.92 ; \mathrm{p}=0.04)$, longer duration of cardiopulmonary bypass $(\mathrm{OR}=1.01 ; \mathrm{p}=0.03)$ and lower preoperative hemoglobin levels $(\mathrm{OR}=0.51 ; \mathrm{p}=0.001)$, ${ }^{9}$ and to Stevens et al., ${ }^{17}$ who reported as predictors: $\mathrm{CKD}$, previous cardiac surgery, urgency surgery, ejection fraction, type of surgery, CPB duration, age and low body mass index, although the last two was not confirmed in our study.

We observed no difference in other infections rates, although higher bronchopneumonia rates have been observed in transfused patients, similarly to TRACS, TRITe2 and Horvath findings. ${ }^{9,10,18}$ We also found longer ICU and hospital lengths of stay, prolonged need for mechanical ventilation, delirium, $\mathrm{ARF}$, acute $\mathrm{CKD}$, stroke and transient ischemic attack in transfused patients. A retrospective Brazilian study on patients with ischemic and valve diseases had already reported higher rates of respiratory infection $(27.8 \%$ vs. $17.1 \% ; \mathrm{p}<0.001)$, ARF (14.5\% vs. $7,3 \% ; \mathrm{p}<0.001)$, stroke $(4.8 \%$ vs. $2.6 \%$; $\mathrm{p}=0.001)$ and longer hospital stay $(13 \pm 12.07$ days vs. $9.72 \pm 7.66$ days; $\mathrm{p}<0.001)$ in transfused patients, but no difference in mortality. ${ }^{19}$

Even though the baseline characteristics were significantly different between the two groups, with transfused patients sicker than not transfused patients, when analyzing transfusion-related mortality, adjusted for the main confounding factors (EuroScore II, age, cardiopulmonary bypass time $\geq 90 \mathrm{~min}$, emergency or urgency surgery and combined surgery), we noticed that transfusion remained an independent predictor of mortality in multivariate logistic regression (OR 5.3; 95\% CI $1.3-21 ; \mathrm{p}<0.001$ ).

Therefore, we emphasize the importance of rethinking the almost routine decision on transfusion in cardiac surgery, taking into account that, even one unit of packaged RBCs, can worsen the postoperative outcomes. 
Table 1 - Baseline characteristics of participants

\begin{tabular}{|c|c|c|c|}
\hline Variable & $\begin{array}{c}\text { Non-transfused } \\
(\mathrm{N}=171) \\
\text { Mean } \pm \text { SD or } \mathrm{N}(\%)\end{array}$ & $\begin{array}{c}\text { Transfused } \\
(\mathrm{N}=100) \\
\text { Mean } \pm \mathrm{SD} \text { or } \mathrm{N}(\%)\end{array}$ & p-value \\
\hline Age (years) & $60.3 \pm 13$ & $63.3 \pm 12.5$ & 1.0 \\
\hline EuroScore II & $2.6 \pm 4$ & $9.6 \pm 12$ & $<0.001$ \\
\hline Male & $111(65 \%)$ & $56(56 \%)$ & 0.218 \\
\hline Caucasians & $159(93 \%)$ & $89(89 \%)$ & 0.595 \\
\hline Weight (kg) & $75 \pm 14$ & $73.2 \pm 16.7$ & 0.307 \\
\hline Height (cm) & $165 \pm 10$ & $164 \pm 10$ & 0.547 \\
\hline Hypertension & $129(75 \%)$ & $73(73 \%)$ & 0.914 \\
\hline Diabetes & $54(31.5 \%)$ & $17(17 \%)$ & 0.683 \\
\hline Chronic kidney disease & $13(7.6 \%)$ & $24(24 \%)$ & $<0.001$ \\
\hline Alcoholism & $5(3 \%)$ & $5(5 \%)$ & 0.573 \\
\hline Smoking & $31(18 \%)$ & $15(15 \%)$ & 0.642 \\
\hline Previous cardiac surgery & $9(5 \%)$ & $16(16 \%)$ & 0.004 \\
\hline Previous myocardial infarction & $45(26 \%)$ & $26(26 \%)$ & 1 \\
\hline Previous stroke & $21(12 \%)$ & $16(16.3 \%)$ & 0.469 \\
\hline Oral anticoagulant or antiplatelet agent (recent use) & $32(18.7 \%)$ & $28(28 \%)$ & 0.086 \\
\hline Left ventricular ejection fraction $\leq 30 \%$ & $8(4.7 \%)$ & $15(15 \%)$ & 0.005 \\
\hline \multicolumn{4}{|l|}{ Preoperative laboratory values } \\
\hline Hemoglobin (g/dL) & $13.5 \pm 1.4$ & $11.8 \pm 2.3$ & $<0.001$ \\
\hline Hematocrit (\%) & $40 \pm 3.7$ & $35.7 \pm 6.4$ & $<0.001$ \\
\hline International normalized ratio & $1.0 \pm 0.2$ & $1.3 \pm 1.0$ & 0.001 \\
\hline aPTT (s) & $26 \pm 3.4$ & $30.5 \pm 15$ & $<0.001$ \\
\hline Urea $(\mathrm{mg} / \mathrm{dL})$ & $45.2 \pm 17$ & $56 \pm 27$ & $<0.001$ \\
\hline Creatinine (mg/dL) & $1.1 \pm 0.4$ & $1.5 \pm 1.4$ & 0.008 \\
\hline Platelet count $(\mu \mathrm{L})$ & $217.000 \pm 55.000$ & $210.000 \pm 85.000$ & 0.392 \\
\hline
\end{tabular}

SD: standard deviation; N: number; EuroSCORE II: European System for Cardiac Operative Risk Evaluation; aPTT: activated partial thromboplastin time; independent samples t-test for continuous variables or chi-square test for categorical variables.

Since most of the risk factors for transfusion cannot be modified, such as surgery type and baseline chronic conditions, it is up to us to focus on those that can be modified or optimized. Thus, Likosky et al., ${ }^{8}$ suggested some strategies to reduce the risk of RBC transfusion, including mini circuits to reduce the prime volume (class I, level A), modified ultrafiltration (class I, level A), antifibrinolytic agents (class IIa, level B), centrifugation of salvaged blood (class IIa, level A), and a team for multidisciplinary blood management (class IIa, level B). ${ }^{8}$

Surgenor et al., ${ }^{7}$ suggested that the use of RBC transfusions in coronary artery bypass graft (CABG) surgery may be reduced by minimizing hemodilutional anemia with preoperative erythropoietin and iron, use of autologous transfusions, preservation of intravenous fluids, avoidance of blood loss, use of a transfusion 
Table 2 - Intraoperative data in transfused and non-transfused patients

\begin{tabular}{lccc}
\hline Variable & $\begin{array}{c}\text { Non-transfused } \\
\mathbf{( N = 1 7 1 )} \\
\text { Mean } \pm \text { SD or N (\%) }\end{array}$ & $\begin{array}{c}\text { Transfused } \\
\text { (N = 100) } \\
\text { Mean } \pm \text { SD or N (\%) }\end{array}$ & p-value \\
\hline Urgency or emergency surgery & $58(34 \%)$ & $61(61 \%)$ & $<0.001$ \\
Combined surgery & $23(13.5 \%)$ & $24(24 \%)$ & 0.003 \\
Procedure & & & 0.124 \\
$\quad$ Coronary artery bypass grafting & $99(58 \%)$ & $45(45 \%)$ & 0.110 \\
$\quad$ Aortic surgery & $11(6.5 \%)$ & $13(13 \%)$ & 0.168 \\
$\quad$ Valve surgery & $64(37.5 \%)$ & $47(47 \%)$ & $<0.001$ \\
Cardiopulmonary bypass time (min) & $70 \pm 22$ & $104 \pm 42$ & $<7 \pm 56$ \\
Cross-clamp time (min) & $54 \pm 22$ & $562 \pm 527$ & $<0.001$ \\
Transoperative bleeding (mL) & $256 \pm 153$ & & \\
\hline
\end{tabular}

SD: standard deviation; independent samples $t$-test for continuous variables and chi-square test for categorical variables.

Table 3 - Types of transfusion $(n=271)$ by the time they were performed (transoperative or during intensive care)

\begin{tabular}{|c|c|c|c|c|c|}
\hline & $\begin{array}{l}\text { Red blood } \\
\text { cell }\end{array}$ & Platelets & $\begin{array}{c}\text { Fresh frozen } \\
\text { plasma }\end{array}$ & Fibrinogen & $\begin{array}{l}\text { Prothrombin } \\
\text { complex }\end{array}$ \\
\hline Transoperative N (\%) & $62(23 \%)$ & $56(20 \%)$ & $32(11.8 \%)$ & $12(4.4 \%)$ & $9(3.3 \%)$ \\
\hline During the intensive care unit stay $\mathrm{N}(\%)$ & $32(12 \%)$ & $10(3.7 \%)$ & $18(6.6 \%)$ & - & - \\
\hline
\end{tabular}

threshold based on patients' physiological needs, achievement of patients' normothermia at the end of the procedure, avoidance of surgeries within 5 to 7 days of the clopidogrel use, performance of prompt coagulation testing to reduce delays in the diagnosis of reversible causes of bleeding. ${ }^{7}$

A recent review article by Patel and Murphy ${ }^{20}$ reinforces the idea that transfusion decision should not be solely based on hemoglobin concentration. The authors report, as potential physiologic triggers, a mean arterial pressure $<60 \mathrm{mmHg}$ (or $<70-80 \%$ of baseline), heart rate $>110-130$ beats $/ \mathrm{min}$ (or $>120-130 \%$ of baseline), new ST-segment depression or elevation of at least $0.1 \mathrm{mV}$ in an electrocardiogram, new wall motion abnormality on transesophageal or transthoracic echocardiography, mixed venous oxygen partial pressure $<32 \mathrm{mmHg}$, oxygen extraction ratio $>40 \%$, mixed venous oxygen saturation $<60 \%$, or $>10 \%$ decrease in oxygen consumption $\left(\mathrm{VO}_{2}\right) \cdot{ }^{20}$
Nowadays, thromboelastography (TEG) and thromboelastometry $\left(\right.$ ROTEM $\left.^{\circledR}\right)$ have been considered of great value in cardiac surgery. Kozek et al., ${ }^{21}$ reported that TEG or ROTEM-guided hemostatic therapy reduces the number of patients requiring RBC, FFP and platelet transfusions, providing a more restrictive strategy than that based on conventional laboratory testing. ${ }^{21}$

The present study has some limitations. This study aimed to report the rates and outcomes of transfusion in daily practice, in a real-life scenario, in which we are challenged by cases not always supported by guidelines' recommendations. Also, there are limitations intrinsic to cohort studies such as its observational nature, in addition to the fact that this was a single-center experience.

\section{Conclusion}

EuroScore II, chronic kidney disease, major transoperative bleeding, preoperative hemoglobin and 
Table 4 - Predictors of transfusion in univariate and multivariate analyses

\begin{tabular}{|c|c|c|c|}
\hline \multicolumn{4}{|c|}{ Univariate analysis } \\
\hline Variable & Odds ratio & $95 \%$ confidence interval & p value \\
\hline Emergency or urgency surgery & 3.1 & $1.8-5.2$ & $<0.001$ \\
\hline Previous cardiac surgery & 3.5 & $1.4-8.2$ & 0.004 \\
\hline EuroScore II & 1.2 & $1.1-1.3$ & $<0.001$ \\
\hline Chronic kidney disease & 3.9 & $1.9-8.1$ & $<0.001$ \\
\hline Left ventricular ejection fraction $\leq 30 \%$ & 3.5 & $1.4-1.8$ & 0.005 \\
\hline Preoperative hemoglobin $\leq 10 \mathrm{~g} / \mathrm{dL}$ & 27 & $6.3-362$ & $<0.001$ \\
\hline Preoperative INR & 17.5 & $3.1-97$ & 0.001 \\
\hline Preoperative aPTT & 1.1 & $1.0-1.2$ & $<0.001$ \\
\hline Preoperative urea & 1.02 & $1.01-1.03$ & $<0.001$ \\
\hline Preoperative creatinine & 1.8 & $1.1-2.9$ & 0.008 \\
\hline Combined surgery & 2.6 & $1.3-5.0$ & 0.003 \\
\hline Cardiopulmonary bypass time & 4.8 & $2.8-8.2$ & $<0.001$ \\
\hline Cross-clamp time & 4.8 & $2.8-8.2$ & $<0.001$ \\
\hline Transoperative bleeding $\geq 500 \mathrm{~mL}$ & 9.6 & $4.6-20$ & $<0.001$ \\
\hline \multicolumn{4}{|c|}{ Multivariate analysis } \\
\hline EuroScore II & 1.2 & $1.0-1.3$ & 0.019 \\
\hline Chronic kidney disease & 3.2 & $1.0-11$ & 0.05 \\
\hline Preoperative hemoglobin $\leq 10 \mathrm{~g} / \mathrm{dL}$ & 11.5 & $1.0-121$ & 0.04 \\
\hline Preoperative aPTT & 1.1 & $1.0-1.2$ & 0.012 \\
\hline Cardiopulmonary bypass time & 1.03 & $1.01-1.06$ & 0.004 \\
\hline Transoperative bleeding $\geq 500 \mathrm{~mL}$ & 6.7 & $2.6-17$ & $<0.001$ \\
\hline
\end{tabular}

aPTT values and duration of cardiopulmonary bypass showed independent predictors for blood transfusion, which was associated with postoperative adverse outcomes, including early mortality.

\section{Author contributions}

Conception and design of the research: Tagliari AP, Cavazzola LT, Wender OCB. Acquisition of data: Tagliari AP, Silveira LMV, Souza AC, Gib MC, Freitas TM, Martins CB. Analysis and interpretation of the data:
Tagliari AP, Kochi AN, Cavazzola LT, Wender OCB. Statistical analysis: Tagliari AP, Kochi AN. Writing of the manuscript: Tagliari AP, Silveira LMV, Kochi AN. Critical revision of the manuscript for intellectual content: Tagliari AP, Silveira LMV, Kochi AN, Souza AC, Gib MC, Freitas TM, Martins CB, Cavazzola LT, Wender OCB.

\section{Potential Conflict of Interest}

No potential conflict of interest relevant to this article was reported. 
Table 5 - Early postoperative outcomes in transfused and non-transfused patients

\begin{tabular}{lccc}
\hline Outcome & $\begin{array}{c}\text { Non-transfused } \\
\mathbf{( N = 1 7 1 )} \\
\text { Mean } \pm \text { SD or N (\%) }\end{array}$ & $\begin{array}{c}\text { Transfused } \\
\mathbf{( N = 1 0 0 )} \\
\text { Mean } \pm \text { SD or N (\%) }\end{array}$ & p value \\
\hline Acute myocardial infarction & $1(0.6 \%)$ & $3(3 \%)$ & 0.288 \\
Delirium & $10(6 \%)$ & $18(18 \%)$ & 0.003 \\
Stroke or transient ischemic attack & $3(1.8 \%)$ & $8(8 \%)$ & $<.029$ \\
Prolonged mechanical ventilation $(\geq 24 \mathrm{~h})$ & $23(23 \%)$ & $<0.001$ \\
Bronchopneumonia & $4(2.4 \%)$ & $16(16 \%)$ & $<0.001$ \\
Acute renal failure & $2(1.2 \%)$ & $25(25 \%)$ & $<0,001$ \\
Acute chronic kidney disease & $6(3.5 \%)$ & $8(8 \%)$ & $<0.001$ \\
New atrial fibrillation & $1(0.6 \%)$ & $18(18 \%)$ & 0.759 \\
Intensive care unit stay (days) & $27(15.8 \%)$ & $7 \pm 9$ & $<0.001$ \\
Hospital length of stay (days) & $3.8 \pm 3$ & $16 \pm 15$ & $<0.001$ \\
Other infections & $8 \pm 4$ & $11(11 \%)$ & 0.57 \\
Death & $14(8.2 \%)$ & $15(15 \%)$ & $<0.001$ \\
\hline
\end{tabular}

M: mean; SD: standard deviation; independent samples t-test for continuous variables and chi-square test for categorical variables.

\section{Sources of Funding}

There were no external funding sources for this study.

\section{Study Association}

This study is not associated with any thesis or dissertation work.

\section{Ethics approval and consent to participate}

This study was approved by the Ethics Committee of the Hospital de Clínicas de Porto Alegre under the protocol number 15-0332. All the procedures in this study were in accordance with the 1975 Helsinki Declaration, updated in 2013. Informed consent was obtained from all participants included in the study.

\section{References}

1. Hutton B, Fergusson D, Tinmouth A, McIntyre L, Kmetic A, Hébert PC. Transfusion rates vary significantly amongst Canadian medical centers. Can J Anaesth. 2005;52(6):581-90.

2. Ferraris VA. Blood transfusion in cardiac surgery: who should get transfused? Lancet Haematol. 2015;2(12):e510-1.

3. Stover EP, Siegel LC, Parks R, Levin J, Body SC, Maddi R, et al. Variability in transfusion practice for coronary artery bypass surgery persists despite national consensus guidelines: a 24-institution study: Institutions of the Multicenter Study of Perioperative Ischemia Research Group. Anesthesiology. 1998;88(2):327-33.

4. Moise SF, Higgins MJ, Colquhoun AD. A survey of blood transfusion practice in UK cardiac surgery units. Crit Care. 2001;5(Suppl A):5.

5. Likosky DS, Zhang M, Paone G, Collins J, DeLucia A 3rd, Schreiber T, et al. Impacto of institucional culture on rates of transfusions during cardiovascular procedures: The Michigan experience. Am Heart J. 2016 Apr;174:1-6.

6. Vonk AB, Meesters MI, van Dijk WB, Eijsman L, Romijn JW, Jansen EK, et al. Ten-year patterns in blood product utilization during cardiothoracic surgery with cardiopulmonary bypass in a tertiary hospital. Transfusion. 2014;54(10 Pt 2):2608-16.

7. Surgenor SD, DeFoe GR, Fillinger MP, Likosky DS, Groom RC, Clark C, et al. Intraoperative red blood cell transfusion during coronary artery bypass graft surgery increases the risk of postoperative low-output heart failure. Circulation. 2006;114(1 Suppl):I43-8.

8. Likosky DS, Paone G, Zhang M, Rogers MA, Harrington SD, Theurer PF et al. Red blood cell transfusions impact pneumonia rates after coronary artery bypass grafting. Ann Thorac Surg. 2015;100(3):794-800.

9. Hajjar LA, Vincent JL, Galas FR, Nakamura RE, Silva CM, Santos $\mathrm{MH}$, et al. Transfusion requirements after cardiac surgery: the TRACS randomized controlled trial. JAMA. 2010;304(14):1559-67.

10. Murphy GJ, Pike K, Rogers CA, Wordsworth S, Stokes EA, Angelini GD, et al. Liberal or restrictive transfusion after cardiac surgery. N Engl J Med. 2015;372:997-1008. 
11. Mazer CD, Whitlock RP, Fergusson DA, Belley-Cote E, Connolly $\mathrm{K}$, Khanykin B, et al. Six-month outcomes after restrictive or liberal transfusion for cardiac surgery. N Engl J Med. 2018;379(13):1224-33.

12. Murphy GJ, Reeves BC, Rogers CA, Rizvi SI, Culliford L, Angelini GD. Increased mortality, postoperative morbidity, and cost after red blood cell transfusion in patients having cardiac surgery. Circulation. 2007;116(22):2544-52.

13. Lumley T, Diehr P, Emerson S, Chen L. The importance of the normality assumption in large public health data sets. Annu Rev Public Health. 2002;23:151-69.

14. Fagerland MW. T-tests, non-parametric tests, and large studies - a paradox of statistical practice? BMC Med Res Methodol. 2012 Jun 14;12:78.

15. Skovlund E, Fenstad GU. Should we always choose a nonparametric test when comparing two apparently nonnormal distributions? J Clin Epidemiol. 2001;54(1):86-92.

16. Goodnough LT, Shah N. Is there "magic" hemoglobin number? Clinical decision support promoting restrictive blood transfusion practices. Am J Hematol. 2015;90(10):927-33.
17. Stevens LM, Noiseux N, Prieto I, Hardy JF. Major transfusions remain frequent despite the generalized use of tranexamic acid: an audit of 3322 patients undergoing cardiac surgery. Transfusion. 2016 Jul;56(7):1857-65.

18. Horvath KA, Acker MA, Chang H, Bagiella E, Smith PK, Iribarne A, et al. Blood transfusion and infection after cardiac surgery. Ann Thorac Surg. 2013;95(6):2194-201

19. Dorneles CC, Bodanese LC, Guaragna JC, Macaganan FE, Coelho JC, Borges AP, et al. The impact of blood transfusion on morbidity and mortality after cardiac surgery. Rev Bras Cir Cardiovasc. 2011;26(2):222-9.

20. Patel NN, Murphy GJ. Transfusion triggers in cardiac surgery: where do we go from here? Can J Anaesth. 2018;65(8):868-72.

21. Kozek-Langenecker SA, Afshari A, Albaladejo P, Santullano CA, De Robertis E, Filipescu DC, et al. Management of severe perioperative bleeding: guidelines from the European Society of Anaesthesiology. Eur J Anaesthesiol. 2013;30(6):270-382. 